\title{
Aspectos Metalúrgicos de Revestimentos Dissimilares com a Superliga à Base de Níquel Inconel 625
}

\author{
(Metallurgical Aspects of Dissimilar Weld Overlays of Inconel 625 Nickel Based Superalloys)
}

\author{
Cleiton Carvalho Silva ${ }^{1}$, Conrado Ramos Moreira Afonso², Antonio Jose Ramirez³, Marcelo Ferreira Mottal , Hélio Cordeiro de \\ Miranda $^{1}$, Jesualdo Pereira Farias ${ }^{1}$ \\ ${ }^{1}$ Universidade Federal do Ceará, Departamento de Engenharia Metalúrgica e de Materiais, Laboratório de Engenharia de \\ Soldagem.,Fortaleza, Ceará,Brasil, cleitonufc@yahoo.com.br, marcelof@ufc.br,hmiranda@ufc.br,jpf@secrel.com.br \\ ${ }^{2}$ Universidade Federal de São Carlos, Departamento de Engenharia de Materiais, São Carlos, São Paulo, Brasil, conrado@ufscar.br \\ ${ }^{3}$ Laboratório Nacional de Luz Síncrotron, Laboratório de Microscopia Eletrônica. Campinas, São Paulo, Brasil, \\ antonio.ramirez@lnls.br
}

\section{Resumo}

Prolongar a vida útil e aumentar a confiabilidade de equipamentos e tubulações de plantas de produção e processamento de petróleo é uma busca constante no setor de petróleo e gás. Tais aspectos dependem essencialmente do uso de ligas resistentes à corrosão. Neste contexto, a soldagem de revestimento com superligas à base de níquel tem sido uma alternativa interessante, pois confere aos equipamentos uma alta resistência à corrosão com um custo inferior, se comparado à fabricação de componentes ou tubulações maciças com superligas. Assim, o objetivo do presente trabalho foi investigar o comportamento metalúrgico de revestimento de superliga à base de níquel do tipo Inconel 625 depositados pelo processo TIG com alimentação de arame frio. As soldagens foram realizadas em uma bancada robotizada, empregando uma fonte eletrônica de soldagem com sistema de aquisição de dados para o monitoramento dos sinais de corrente e tensão. A caracterização microestrutural foi realizada através das técnicas de microscopia eletrônica de varredura (MEV) e transmissão (MET), espectroscopia de energia dispersiva de raios-X (EDS). Os resultados mostraram que a microestrutura do metal de solda foi constituída por uma matriz $\gamma$ com fases secundárias ricas em $\mathrm{Nb}$. Foi encontrada a formação de precipitados complexos de carbonetos/nitretos de Ti e $\mathrm{Nb}$.

Palavras-chave: Soldagem de revestimento; Superliga; Microestrutura; Inconel 625.

\begin{abstract}
To extend the life and reliability of pipes and equipment in oil \& gas production and processing settings is a continuous demand. These aspects are essentially dependent on corrosion resistant alloys used. In this context, the weld overlay with Ni-based superalloys is a great interesting alternative, since improve the corrosion resistance without increase the cost of manufacture when compared to massive equipment. Thus, the objective of this study was to evaluate the metallurgical aspects of Inconel 625 weld overlays deposited by GTAW cold wire feed process. The welds were performed using a robotic workbench, an electronic power supply and a data acquisition system. The microstructural characterization was carried out using scanning electron microscopy (SEM), transmission electron microscopy (MET), electron dispersive spectroscopy (EDS) and X-ray diffraction. The results shown that the microstructure of overlays was formed by a gamma matrix and secondary phases rich in $\mathrm{Nb}$. These precipitates were identified as Nb-rich Laves phase and a complex TiN/NbC.
\end{abstract}

Key-words: Welding overlay; Superalloys; Microstructure; CRA; Inconel 625.

\section{Introdução}

Superligas à base de níquel constituem uma importante classe de materiais de engenharia, por combinarem elevada resistência mecânica à alta temperatura com excelente resistência à oxidação, o que as tornaram especialmente destinadas a aplicações em alta temperatura, notadamente na construção de turbinas a jato [1]. Posteriormente, outras importantes propriedades,

(Convidado em 15/05/2012; Texto final em 27/08/2012). como sua elevada resistência à corrosão em diversos meios, as tornaram aplicáveis em vários outros setores industriais [2-4]. Esta alta resistência à corrosão é alcançada similarmente aos aços inoxidáveis através da formação de um filme passivo de óxido de cromo sobre a superfície da liga, protegendo o material contra a ação do meio corrosivo $[5,6]$. Outros elementos como Mo, Al e W também podem participar da formação da camada passivadora, contribuindo para o aumento da resistência à corrosão, especialmente corrosão localizada $[7,8]$. No entanto, como o preço destas ligas é elevado, o custo passa a ser um fator limitante para o uso destas ligas.

Neste contexto, a soldagem de revestimento torna-se uma excelente opção para a fabricação de equipamentos para 
inúmeros setores industriais, cujas superfícies internas ou externas necessitam de características específicas para garantir um bom desempenho em serviço, como por exemplo, resistência à corrosão [9]. A deposição destes revestimentos constitui um procedimento complexo do ponto de vista metalúrgico, no qual ocorre a fusão e a solidificação de um volume de metal composto por duas diferentes ligas em termos de composição química, estrutura cristalina, microestrutura e propriedades físicas e mecânicas, a qual é denominada de soldagem dissimilar. Além disso, as ligas à base de níquel têm sido utilizadas também na união de componentes de materiais dissimilares de alta responsabilidade, como no caso das indústrias petroquímicas, nucleares e de petróleo e gás [10].

Dentro do universo das superligas à base de níquel, a família Ni-Cr-Mo representa uma das mais importantes em termos de resistência à corrosão. Segundo Hodge [11], esta família de superligas de Ni são tipicamente aplicadas quando a presença de impurezas no sistema, especialmente sais, alcançam valores onde as classes com menores teores de molibdênio sofrem corrosão localizada. Sua resistência à corrosão é significativamente maior que a dos aços inoxidáveis quando expostos a alta temperatura, aplicadas em equipamentos de processamento químico e petroquímico, equipamentos de refinarias de petróleo e gás, trocadores de calor resfriados com água do mar e equipamentos para processamento de fluidos ácidos e contendo elevados teores de sais.

Dentre os inúmeros representantes da família Ni-Cr-Mo, a liga Inconel 625 ocupa posição de destaque, tendo sido desenvolvida em 1964, na primeira geração das ligas à base de Ni. Inicialmente desenvolvida para operações em alta temperatura, logo teve sua aplicação estendida para várias outras aplicações devido à descoberta de sua excelente resistência à corrosão a uma grande variedade de meios corrosivos, o que possibilitou o seu emprego em diversos setores da indústria [12]. Tal comportamento se deve principalmente ao alto teor de $\mathrm{Cr}(20 \%)$ e adição de Mo (9\%). Seus teores de ferro e carbono são limitados a níveis baixos para manter as propriedades de resistência à corrosão e para minimizar a precipitação nos contornos de grão, evitando problemas de corrosão localizada, especialmente em componentes soldados [13].

Contudo, tais propriedades somente são alcançadas para materiais no estado solubilizado, o que não é o caso de metais depositados por solda [14-16]. De fato, inúmeros trabalhos têm reportado que em metais de solda com alta liga, como os aços inoxidáveis e as ligas à base de $\mathrm{Ni}$, a resistência à corrosão pode ser afetada através de segregação de elementos como o Cr e o Mo durante solidificação $[17,18]$. Outro fator que pode afetar o comportamento destas ligas é o efeito da diluição da superliga com o ferro contido no metal de base, no caso de soldas dissimilares [19].

Ainda com respeito à soldagem dissimilar, a interface entre as superligas à base de níquel e aços carbono e baixa liga constitui uma região de grande interesse, por se tratar de um local onde existe uma significativa mudança microestrutural, um considerável gradiente químico, e a presença de regiões críticas em termos de propriedades mecânicas, estando muitas vezes associadas à problemas como fragilização por hidrogênio, perda de tenacidade, descolamento, corrosão sob-tensão e corrosão [20-23]. Além disso, é a partir desta região que se inicia o processo de solidificação do metal líquido. Esta região de transição é resultante da incompleta mistura entre materiais com diferença significativa de composição química.

Ainda assim, devido a sua excelente resistência à corrosão o uso de ligas Ni-Cr-Mo tem sido considerado interessante para aplicações em soldagens de revestimento sobre aços carbono, C-Mn e baixa liga. No entanto, poucas investigações sobre a soldagem dissimilar destas ligas com aços C-Mn e baixa liga têm sido publicadas na literatura. No presente trabalho foram investigados os aspectos metalúrgicos que estão diretamente relacionados à microestrutura final de revestimentos dissimilares de ligas de níquel do tipo Inconel $625 \mathrm{com}$ aço C-Mn.

\section{Procedimento Experimental}

\subsection{Materiais}

O metal de adição usado para a deposição da camada de revestimento foi o arame AWS ER-NiCrMo-3 com 1,2 mm de diâmetro, o qual corresponde à liga Inconel 625. Como substrato foi utilizado o aço ASTM A516 Gr.60, o qual é empregado na construção de equipamentos para indústrias químicas, petroquímicas e de petróleo e gás. A composição química de ambos os materiais encontra-se na Tabela 1. A deposição por soldagem foi realizada através do processo TIG com alimentação de arame frio. Utilizou-se um eletrodo de tungstênio dopado com tório, com $4 \mathrm{~mm}$ de diâmetro. Como gás de proteção foram utilizadas duas misturas, uma de argônio com $0,01 \%$ de óxido nítrico e outra de argônio com 30\% de hélio.

\subsection{Metodologia}

Foi utilizada uma fonte de soldagem eletrônica multiprocesso juntamente com um sistema de aquisição de dados para o monitoramento da corrente e da tensão durante a soldagem. A manipulação da tocha foi realizada através de um sistema robótico industrial, conforme mostrado na Figura 1a. Um sistema de alimentação automática de arame para soldagem TIG e Plasma foi utilizado para o fornecimento do metal de adição. Uma unidade de posicionamento foi usada para guiar o arame para o interior do arco e possibilitar o ajuste da configuração e geometria da alimentação de arame (Figura 1b).

Os revestimentos foram produzidos através da deposição de cordões de solda dispostos lado a lado, com uma sobreposição parcial do cordão subsequente sobre o cordão depositado anteriormente. Estudos preliminares mostraram que a distância ótima entre o centro dos cordões de solda para proporcionar uma sobreposição adequada foi de $2 / 3$ da largura do primeiro cordão de solda depositado [24]. 
Tabela 1. Composição química do metal de adição e metal de base.

\begin{tabular}{|c|c|c|c|c|c|c|c|c|}
\hline Item & \multicolumn{7}{|c|}{ Composição química (\% em peso) } \\
\hline \multirow{2}{*}{$\begin{array}{c}\text { AWS ER NiCrMo-3 } \\
\left.\text { (Inconel } 625^{\circ}\right)\end{array}$} & $\mathrm{Ni}$ & $\mathrm{C}$ & $\mathrm{Cr}$ & $\mathrm{Mo}$ & $\mathrm{Nb}$ & $\mathrm{Fe}$ & $\mathrm{Mn}$ & $\mathrm{Si}$ \\
\cline { 2 - 10 } & 64,43 & 0,011 & 22,2 & 9,13 & 3,53 & 0,19 & 0,01 & 0,05 \\
\hline \multirow{2}{*}{ ASTM A516 Gr. 60} & $\mathrm{Ni}$ & $\mathrm{C}$ & $\mathrm{Cr}$ & $\mathrm{Mo}$ & $\mathrm{Fe}$ & $\mathrm{Al}$ & $\mathrm{Mn}$ & $\mathrm{Si}$ \\
\cline { 2 - 9 } & 0,01 & 0,15 & 0,02 & 0,01 & $\mathrm{Bal}$ & 0,02 & 0,95 & 0,2 \\
\hline
\end{tabular}
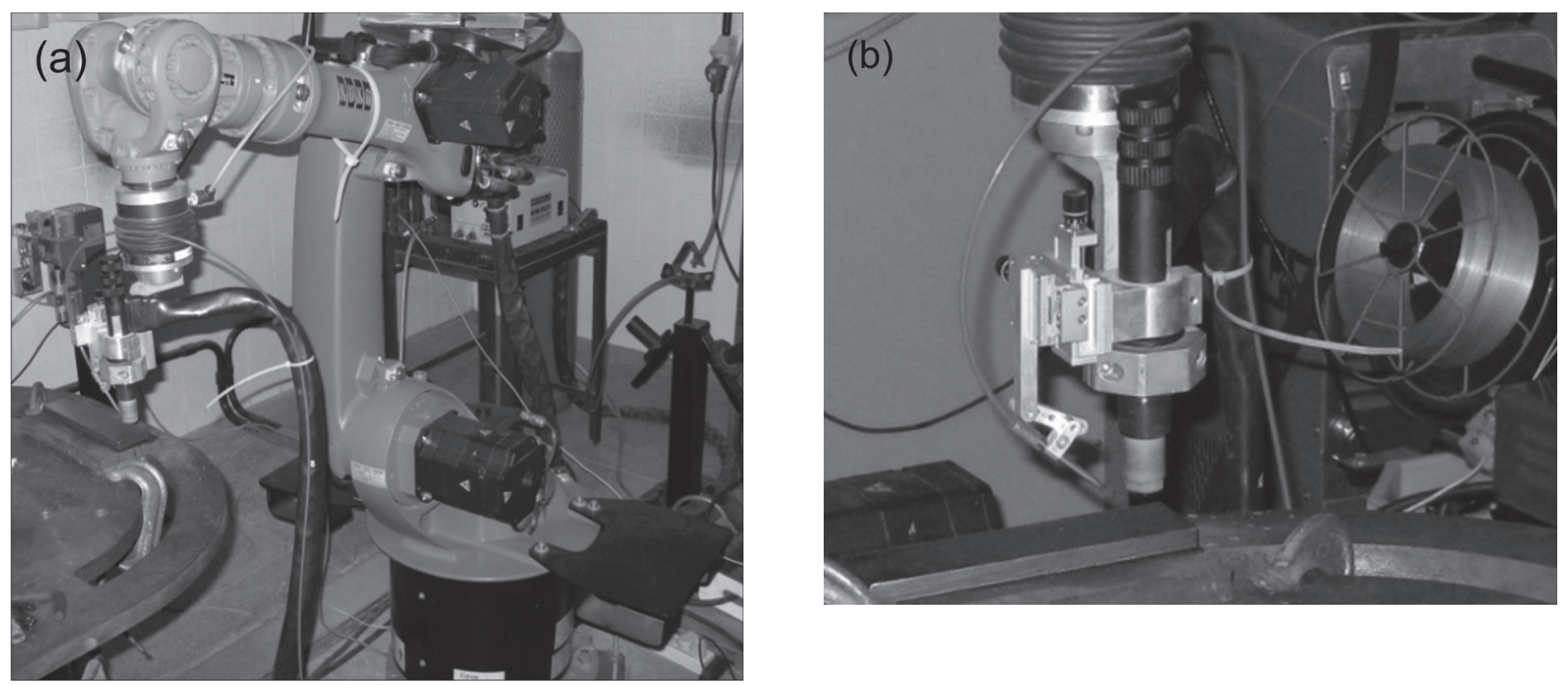

Figura 1. (a) Sistema robótico. (b) Detalhe do sistema guia de alimentação de arame e da tocha TIG.

Tabela 2. Parâmetros de soldagem utilizados nos ensaios.

\begin{tabular}{|c|c|c|c|c|c|c|c|}
\hline Ensaio & $\begin{array}{c}\text { Corrente } \\
\text { Eficaz Ie } \\
(\mathrm{A})\end{array}$ & $\begin{array}{c}\text { Velocidade de } \\
\text { soldagem Vs } \\
(\mathrm{cm} / \mathrm{min})\end{array}$ & $\begin{array}{c}\text { Tensão } \\
\text { Eficaz U } \\
(\mathrm{V})\end{array}$ & $\begin{array}{c}\text { Energia de } \\
\text { soldagem } \\
(\mathrm{kJ} / \mathrm{cm})^{*}\end{array}$ & $\begin{array}{c}\text { Velocidade de } \\
\text { alimimentação de } \\
\text { arame }(\mathrm{m} / \mathrm{min})\end{array}$ & Gás de proteção & Tecimento \\
\hline 1 & 285 & 21 & 21,5 & 11,2 & 7,0 & $\mathrm{Ar}+30 \% \mathrm{He}$ & Duplo 8 \\
\hline 3 & 385 & 21 & 23,3 & 16,8 & 10,0 & $\mathrm{Ar}+30 \% \mathrm{He}$ & Triangular \\
\hline
\end{tabular}

*Rendimento térmico do processo TIG considerado igual a 0,65 .

Após as soldagens foram extraídas amostras para preparação metalográfica convencional através de lixamento e polimento mecânico. A revelação da microestrutura foi conseguida através de ataque eletrolítico utilizando-se uma solução de ácido crômico $10 \%$, tensão de $2,0 \mathrm{~V}$ e tempo de ataque de 15 segundos. A caracterização foi realizada através de microscopia eletrônica de varredura (MEV). Amostras de lâmina fina também foram extraídas do metal de solda e preparadas segundo a técnica de secção transversal para posterior observação em microscopia eletrônica de transmissão (MET). Análises químicas de espectroscopia de energia dispersiva de raio-X (EDS) foram realizadas em ambas as técnicas de microscopia.

\section{Resultados e Discussão}

A soldagem de revestimentos de materiais dissimilares (Figura 2a) resulta na formação de pelo menos três importantes regiões de interesse do ponto de vista investigativo, que são a zona fundida (Figura 2b), a interface revestimento/substrato (Figura 2c) e a zona afetada pelo calor (Figura 2d). Cada uma destas regiões apresentam alterações metalúrgicas específicas e comportamentos distintos em função das exigências em termos de solicitação, quer seja por esforços mecânicos e/ou degradação. No presente trabalho serão detalhadas os principais aspectos metalúrgicos relacionados às duas primeiras regiões citadas anteriormente, ou seja, zona fundida e interface revestimento substrato. 
(a)
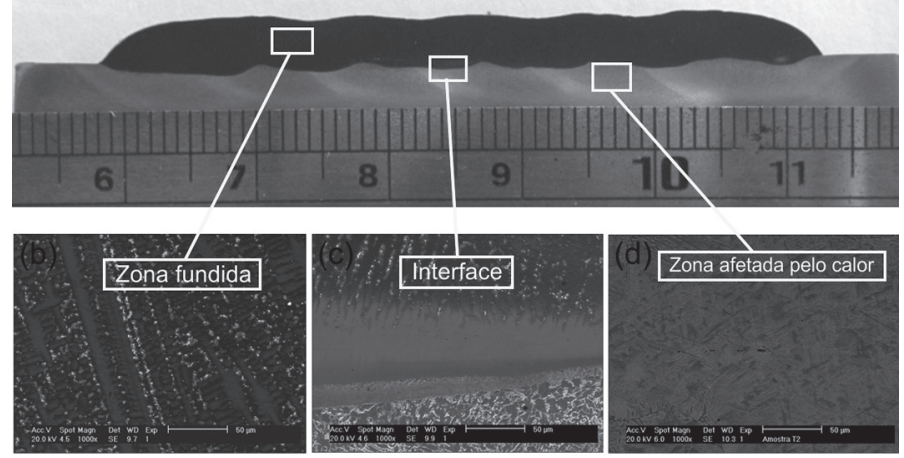

Figura 2. (a) Macrografia da seção transversal de um revestimento depositado com a superliga Inconel 625; (b) Micrografia da zona fundida de Inconel 625; (c) Interface Inconel 625/Aço ASTM A516 Gr. 60; (d) Micrografia da ZAC do aço ASTM A516 Gr. 60.

\subsection{Microestrutura da interface}

A investigação sobre a microestrutura dos revestimentos iniciou-se pela interface revestimento/substrato. Avaliando detalhadamente a região da interface foi possível observar nitidamente os limites entre os dois materiais (Liga de níquel e aço C-Mn). Contudo, no interior da zona fundida imediatamente após a linha de fusão é notória a presença de uma zona de transição, constituída por uma faixa clara, cuja extensão varia de algumas dezenas de microns. Esta zona de transição é composta por duas regiões distintas: uma lisa, na qual não são observadas as presenças tanto de contornos de grão como de interfaces entre células ou dendritas, e cuja morfologia sugere ter solidificado de forma planar; e posteriormente existe uma segunda zona, desta vez com características de crescimento celular, conforme observado na Figura 3. Por fim, tem-se o volume do metal de solda cuja morfologia varia entre celular dendrítico e colunar dendrítico. Esta zona de transição tem recebido diversos nomes na literatura, sendo no presente trabalho referida como zona parcialmente misturada (ZPM).

Através de análise química por EDS foi possível determinar a composição química da ZPM. Como pode ser observado na Figura 4, a região clara apresenta uma transição em termos de composição química entre o aço e a liga Inconel 625. Avaliando inicialmente o canto inferior direito tem-se o aço cuja composição é praticamente constituída por ferro. Seguindo a avaliação da direita para a esquerda, tem-se inicialmente uma composição constituída quase $100 \%$ de $\mathrm{Fe}$, correspondendo ao metal de base de aço C-Mn. Em seguida, observa-se a "zona de transição", cujo teor de ferro cai rapidamente ao longo da sua extensão, estabilizando em aproximadamente $10 \%$ após deixar a ZPM. O níquel cresce rapidamente alcançando ao final da transição um teor de aproximadamente $56 \%$, estabilizando neste valor. Os demais elementos como $\mathrm{Cr}$, Mo e $\mathrm{Nb}$ crescem em uma menor taxa e também estabilizam após saírem da ZPM. Com base nestes resultados, pode-se afirmar a existência de uma zona constituída por uma estrutura austenitica (cfc) rica em Fe, a qual foi estabilizada à temperatura ambiente pela incorporação parcial de Ni oriundo do metal de adição. Posteriormente, com o aumento da concentração de Ni tem-se a matriz constituída pela matriz g, também com estrutura cristalina cfc. Do ponto de vista cristalográfico, não foram observadas variações de orientação entre estas zonas, sendo as variações encontradas apenas de ordem composicional. Maiores detalhes sobre a cristalografia destas interfaces podem ser encontrados em Silva et al. [25].

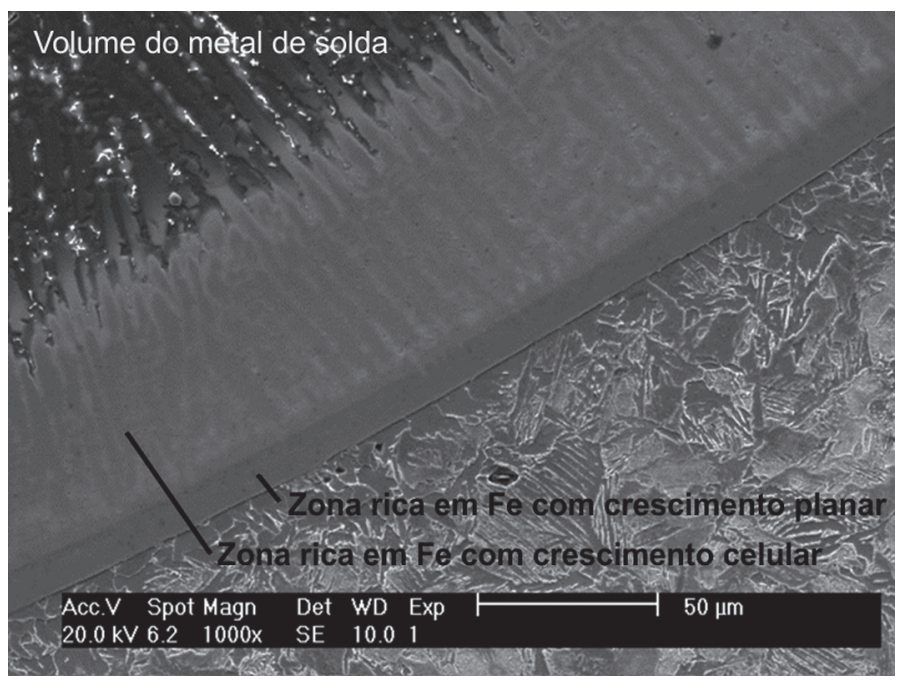

Figura 3. Interface revestimento/substrato indicando a formação de uma zona de transição (ZPM).

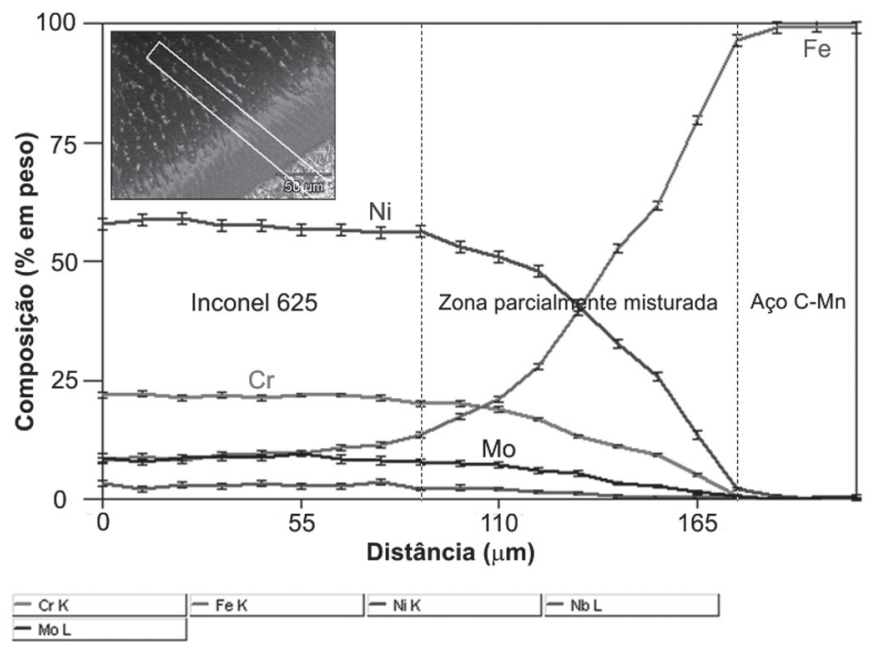

Figura 4. Perfil de composição química ao longo da interface (\% em peso).

A incompleta mistura entre o volume líquido do metal de solda e o metal de base fundido no contorno da poça de fusão e o gradiente de composição química observado na ZPM pode ser atribuído ao mecanismo de escoamento do metal líquido no interior da poça de fusão. Segundo os conceitos da mecânica dos fluidos, um líquido escoando sobre uma superfície sólida apresenta uma zona cuja velocidade varia desde a velocidade de escoamento até zero na adjacência com o sólido, a qual é denominada de camada limite [26]. Desta forma, mesmo no caso da soldagem, no qual a ação de diversas forças motrizes 

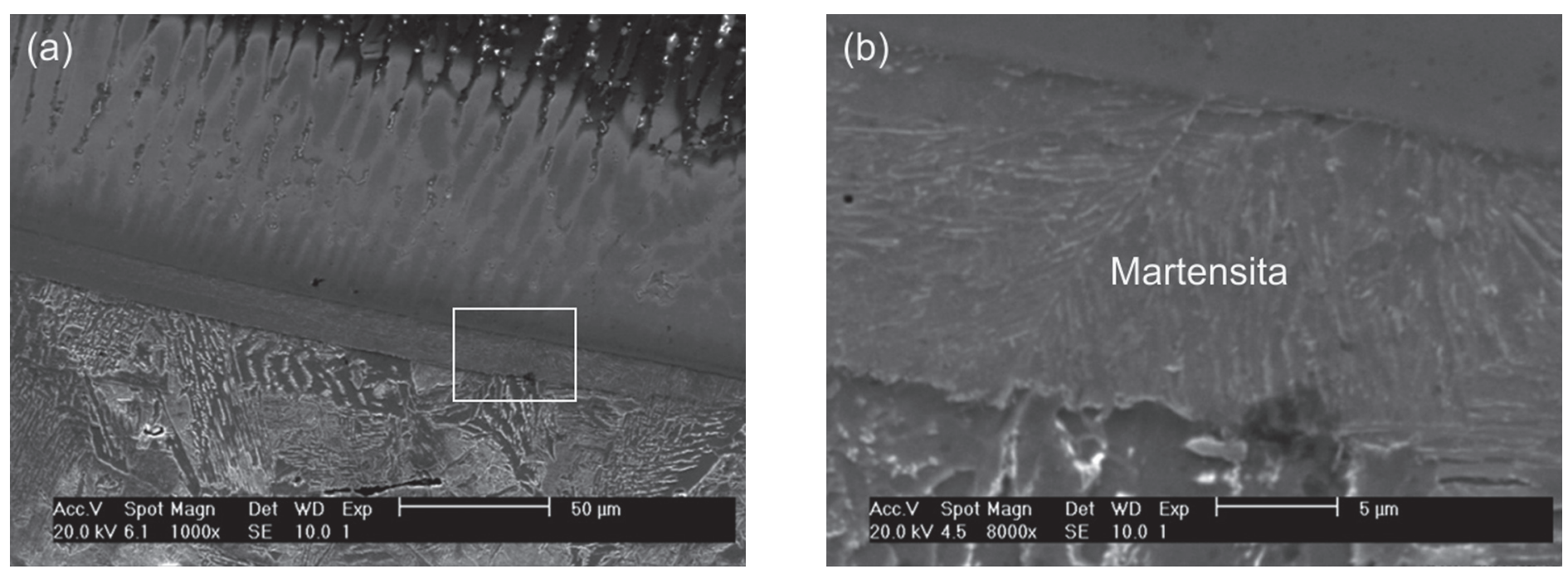

Figura 5. (a) Zona parcialmente misturada com formação de martensita ao longo da interface revestimento/substrato. (b) Detalhe ampliado da Figura 5 a

causa uma intensa agitação do metal líquido na poça de fusão, ainda assim, na linha de fusão onde a agitação é enfraquecida, o líquido pode encontrar-se estagnado ou sob escoamento laminar, impedindo assim, sua completa mistura [27].

Como não ocorre a mistura completa entre os dois materiais, um gradiente de composição química é observado. As possíveis razões para a existência deste gradiente de composição têm sido atribuídas principalmente ao processo difusional entre os dois líquidos - metal de solda e metal de base na fase líquida, embora a mistura mecânica parcial entre os dois líquidos e a segregação de soluto durante a solidificação também sejam apontadas como possíveis fatores [28,29].

No âmbito das interfaces na soldagem dissimilar, diversas zonas com características distintas têm sido observadas. No entanto, uma dentre as demais tem merecido maiores atenções, que são as zonas nas quais são observadas a formação de martensita com consequente aumento de dureza. Esta zona é denominada no presente trabalho como ZPM-M. A Figura 5 apresenta um exemplo de zona parcialmente misturada com formação de martensita (ZPM-M). Os aspectos composicionais desta zona são mais complexos e resultam da incorporação de quantidades muito pequenas de elementos de liga como $\mathrm{Cr}$, Mo e especialmente o $\mathrm{Ni}$, a qual não é suficiente para estabilizar a estrutura austenítica, como no caso anterior, mas suficiente para elevar a temperabilidade, proporcionando a transformação martensítica. Maiores detalhes sobre a formação destas zonas podem ser encontrados em [24].

Beaugrand et al. [30] têm estudado a soldagem dissimilar entre um aço baixa liga forjado e a liga de Níquel 625 para aplicações submarinas e tem dado atenção especial à caracterização da microestrutura e aos mecanismos de falha que podem ocorrer na ZPM. Kejelin et al. [31] considerando a soldagem dissimilar entre a liga 625 e tubos de aço API 5L X60, verificou através do diagrama de Schaeffler que a máxima diluição permitida para evitar a formação de martensita na zona fundida seria de $70 \%$, considerando a diluição global. Contudo, mesmo nas condições em que o nível de diluição global foi bem abaixo do máximo permitido (70\%), houve a ocorrência de zonas M. Os autores atribuíram tal observação ao fato de que localmente a interface apresenta níveis de diluição bem mais altos que 70\%. Silva et al. [32] estudaram o efeito de diversos aspectos operacionais sobre a formação destas zonas e verificaram que de fato a diluição global não tem relação direta com a formação destas ZPM's, tendo sido observado quantidades diferentes de ZPM's ao longo da interface independente do nível de diluição. Os resultados apontaram a convecção da poça de fusão e a agitação do metal líquido nas proximidades da interface como o principal fator responsável pela formação das ZPM's.

\subsection{Microestrutura da zona fundida}

Um aspecto importante a ser considerado na soldagem de materiais similares é a composição química global da zona fundida. No presente trabalho, a composição das soldas depositadas foram obtidas por fluorescência de raio-X (FRX), cujos resultados são apresentados na Tabela 3 . As medidas foram realizadas na superfície do revestimento a 3,0 $\mathrm{mm}$ da interface revestimento/substrato, de acordo com a norma API 10423 [33]. Com base nos resultados de composição química, especialmente os teores de $\mathrm{Fe}$ dos revestimentos, obtidos através de análise química de FRX, foram determinados os níveis de diluição para cada condição de soldagem aplicada. A diluição foi determinada através da Equação I, onde: $\mathrm{C}_{\mathrm{ms}}$ constitui a concentração do elemento, no caso o Fe, no metal de solda; $\mathrm{C}_{\text {ma }}$ é a concentração do elemento no metal de adição; e $\mathrm{C}_{\mathrm{mb}}$ é a concentração do elemento no metal de base. Para o metal de base (substrato) o teor de ferro foi de 98,2\%. Já os tores de Fe no metal de adição foi de $0,19 \%$. A diluição também foi determinada por análise de imagem da seção transversal. Ambos os resultados são apresentados na Tabela 3 .

$D=\frac{C_{m s}-C_{m a}}{C_{m b}-C_{m a}}$ 
Tabela 3. Composição química global da zona fundida dos revestimentos depositados e diluição.

\begin{tabular}{|c|c|c|c|}
\hline \multirow{2}{*}{\multicolumn{2}{|c|}{1}} & \multicolumn{2}{|c|}{ Ensaios } \\
\hline & & 3 & \\
\hline \multirow{7}{*}{$\begin{array}{l}\text { Composição química } \\
\text { (\% em peso) }\end{array}$} & $\mathrm{Ni}$ & 58,5 & 55,6 \\
\hline & $\mathrm{Cr}$ & 21,1 & 14,8 \\
\hline & Mo & 8,1 & 8,8 \\
\hline & $\mathrm{Nb}$ & 3,2 & 2,2 \\
\hline & $\mathrm{Fe}$ & 8,0 & 17,9 \\
\hline & $\mathrm{Si}$ & 0,26 & 0,23 \\
\hline & $\mathrm{Ti}$ & 0,24 & 0,17 \\
\hline \multirow{2}{*}{ Diluição (\%) } & $\begin{array}{l}\text { Via análise } \\
\text { química }\end{array}$ & 8,0 & 18,0 \\
\hline & $\begin{array}{l}\text { Via análise } \\
\text { de imagem }\end{array}$ & 9,1 & 15,4 \\
\hline
\end{tabular}

De acordo com a análise química, é observado que a medida que a concentração de $\mathrm{Fe}$ aumenta os teores de Ni diminuem. As amostras tiveram uma variação da ordem de 5\% do teor de $\mathrm{Cr}$ em função da diluição, sendo observado $14,8 \%$ de $\mathrm{Cr}$ na amostra 3, cujo teor de Fe foi de 17,9, enquanto a amostra 1 alcançou um teor de Cr de 21,1\%, para $8,0 \%$ de Cr. Já o teor de Mo permaneceu praticamente estável variando entre 8,1 e $8,8 \%$. $\mathrm{O} \mathrm{Nb}$ sofreu uma redução de $3,1 \%$ para 2,2\% com o aumento da diluição. Outros elementos minoritários foram detectados como o $\mathrm{Ti}$ e o $\mathrm{Si}$, cujos teores variaram entre 0,17 a $0,24 \%$, e entre 0,23 a $0,26 \%$, respectivamente. Quanto à diluição, verifica-se que os níveis aumentaram da condição 1 para a condição 3 . Em termos de parâmetros de soldagem, as três condições apresentam níveis crescentes de energia de soldagem. Isto poderia indicar uma relação direta entre o aumento da energia de soldagem e o crescente nível de diluição apresentado pelos metais de solda. No entanto, é importante destacar que as amostras investigadas no presente trabalho são oriundas de um estudo mais amplo visando a deposição de revestimentos com baixo nível de diluição (teor de Fe inferior a 5\%), tendo sido comprovado que em se tratando de diluição outras variáveis do processo podem influenciar sobremaneira o nível de diluição do metal depositado, e que condições de baixa diluição podem ser depositadas ainda que sejam aplicados níveis elevados de energia de soldagem [34].

A microestrutura dos revestimentos de superligas Inconel 625 na condição como soldada apresentou comportamento relativamente complexo, sendo formadas pela matriz $\gamma$ e fases secundárias precipitadas nas regiões intercelulares e interdendriticas. Aspectos morfológicos dos precipitados observados nas várias amostras soldadas indicaram a ocorrência de dois principais tipos de fases secundárias nos revestimentos com a superliga Inconel 625, precipitados com morfologia cuboidal e precipitados multiforme (bastonetes e eutéticos lamelares) como pode ser observado na Figura 6.

Na Figura 7a são apresentados pequenos precipitados com morfologia em forma de blocos e aspecto cúbico tipicamente encontrado nas amostras avaliadas. Estes precipitados foram encontrados tanto aprisionados próximo aos centros das dendritas quanto nas regiões interdendríticas, mas em alguns casos eles podem ocorrer também próximo aos contornos de grão de solidificação. A análise química por EDS (Figura 7b) indicou que tais precipitados são ricos em $\mathrm{Ni}, \mathrm{Cr}$, Mo, e principalmente $\mathrm{Nb}$, visto que o teor de $\mathrm{Nb}$ da liga é de aproximadamente $4 \%$, e os resultados de EDS indicaram teores de $\mathrm{Nb}$ de $23 \%$ nos precipitados. Os elementos $\mathrm{Ni}, \mathrm{Cr}$ e Mo são os constituintes principais da liga e podem aparecer em teores relativamente altos devido à interação de elétrons do feixe com a matriz, mesmo quando o ponto de análise esteja sobre o precipitado. Também foi observada a presença de Ti $(0,95 \%)$, o qual é um elemento conhecido por ser um forte formador de carbonetos e nitretos.

Outra observação importante foi a presença considerável de $\mathrm{C}(1,3 \%)$, que embora seja um elemento leve e sua quantificação por análise de EDS não seja correta, o fato do espectro apresentar um pico deste elemento pode ser um indicativo de que o precipitado seja um carboneto rico em $\mathrm{Nb}$. Embora o teor de $\mathrm{C}$ destas ligas seja controlado durante a sua produção para conservá-los em níveis significativamente baixos, o percentual deste elemento na liga diluída pode ser elevado consideravelmente devido à mistura com o substrato, o qual apresenta aproximadamente $0,2 \% \mathrm{C}$.
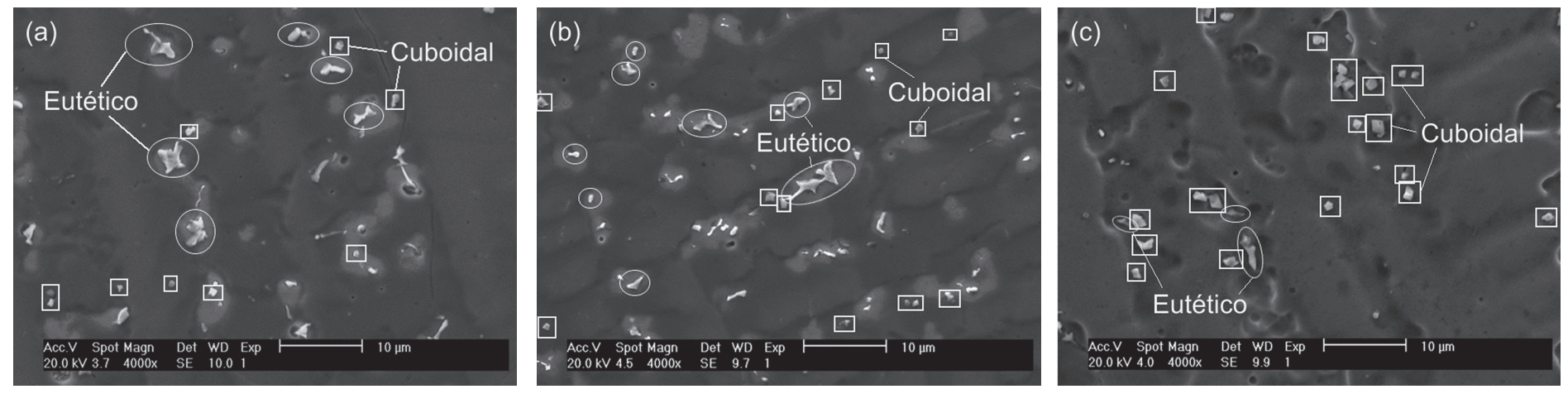

Figura 6. Micrografia obtida por MEV usando o modo elétrons secundários a qual apresenta precipitados eutéticos rodeados por círculos pontilhados e precipitados com morfologia cuboidal rodeados por retângulos pontilhados, ambos precipitados na matriz $\mathrm{g}$. 

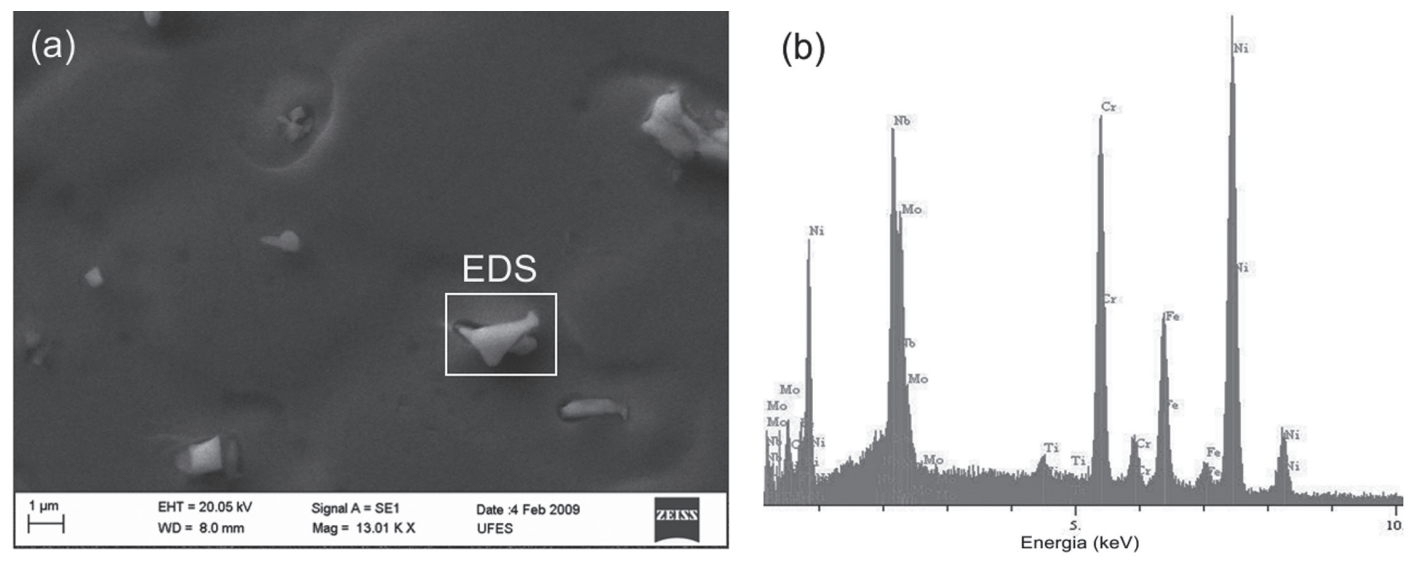

(c)
\begin{tabular}{|l|l|}
\hline Elemento & $\begin{array}{l}\text { Concentração } \\
(\% \text { peso })\end{array}$ \\
\hline $\mathrm{Ti}$ & 1,0 \\
\hline $\mathrm{V}$ & 0,08 \\
\hline $\mathrm{Cr}$ & 16,1 \\
\hline $\mathrm{Fe}$ & 10,4 \\
\hline $\mathrm{Ni}$ & 39,0 \\
\hline $\mathrm{Nb}$ & 23,3 \\
\hline $\mathrm{Mo}$ & 8,9 \\
\hline
\end{tabular}

Figura 7. (a) Imagem de MEV no modo SE apresentando em destaque precipitados com aspecto cúbico; (b) Análise de EDS de um precipitado cúbico; (c) Resultado semi-quantitativo da análise química de EDS (\% em peso).
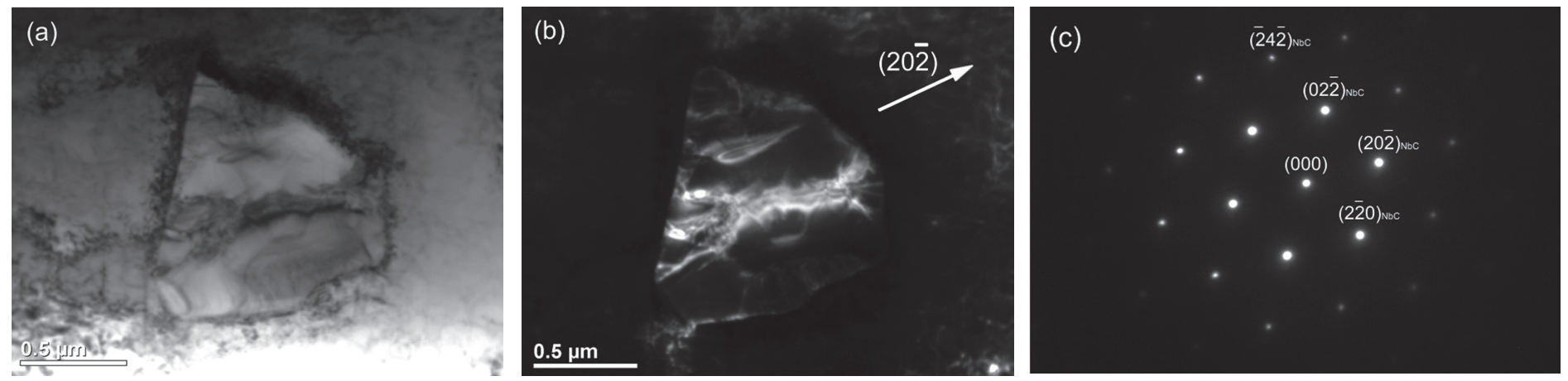

Figura 8. (a) Imagem do carbonitreto de Ti Nb em campo claro. (b) Imagem do precipitado em campo escuro na direção (20-2). (c) Padrão de difração de elétrons do precipitado indexado como NbC no eixo de zona [111].

Análises de microscopia eletrônica de transmissão (MET) foram realizadas em alguns precipitados com morfologia cuboidal encontrados na matriz g. Uma destas análises encontrase na Figura 8a. Nesta imagem obtida no modo de operação de campo claro não é possível observar claramente qualquer alteração no contraste que revelasse a presença de duas ou mais fases no mesmo precipitado. A imagem apresentada na Figura 8b foi obtida no modo de operação com campo escuro, cuja imagem foi produzida através do feixe referente ao plano difratado (202). O padrão de difração de elétrons de área selecionada (SAD) do precipitado é apresentado na Figura 8c. Em ambos os modos de operação as imagens indicam que, a princípio, o precipitado é constituído por uma única fase.

Operando o MET no modo varredura foi possível produzir um mapa de composição química via EDS deste precipitado, a qual indicou uma importante informação sobre a distribuição de diversos elementos no interior da partícula. Avaliando os mapas de composição com distribuição em \% em peso, foi possível verificar que o precipitado apresenta empobrecimento dos elementos Ni, Cr, Mo e Fe (Figura 9), enquanto C, N, Nb e Ti se encontram concentrados sobre a partícula. No entanto, a informação mais importante desta análise química está relacionada à evolução química do precipitado. Como pode ser observado nos mapas dos elementos $\mathrm{Ti}$ e $\mathrm{Nb}$, houve uma clara separação entre estes elementos no interior do precipitado, sendo o Ti concentrado ao centro formando um núcleo e o $\mathrm{Nb}$ distribuído ao redor deste núcleo rico em $\mathrm{Ti}$, formando um invólucro. O nitrogênio apresentou comportamento semelhante ao do titânio, concentrando-se ao centro do precipitado.

Este resultado indica fortemente que os precipitados com morfologia cúbica ricos em $\mathrm{Ti}$ e $\mathrm{Nb}$ observados nos revestimentos depositados com a liga 625 não são carbonitretos do tipo $(\mathrm{NbTi})(\mathrm{CN})$ como suposto em alguns poucos trabalhos na literatura, mas sim um precipitado complexo, composto por um núcleo de nitreto de Ti (TiN) ou Ti e $\mathrm{Nb}(\mathrm{TiNb}) \mathrm{N}$ e uma casca de carboneto de $\mathrm{Nb}$ e $\mathrm{Ti}(\mathrm{NbTi}) \mathrm{C}$. Dados da literatura indicam que a temperatura de fusão do nitreto de titânio TiN é de $2.927^{\circ} \mathrm{C}$ [35], praticamente o dobro da temperatura de fusão da liga. Este dado indica que nas temperaturas convencionais para o metal no estado líquido durante a soldagem os nitretos TiN não são dissolvidos. Desta forma, as partículas de nitretos permanecem sólidas e passam a atuar no interior do líquido como agentes nucleantes para o crescimento de carbonetos contendo $\mathrm{Nb}$. Maiores detalhes sobre a formação destes precipitados complexos podem ser encontrados em Silva [24] e Silva et al. [36]. 

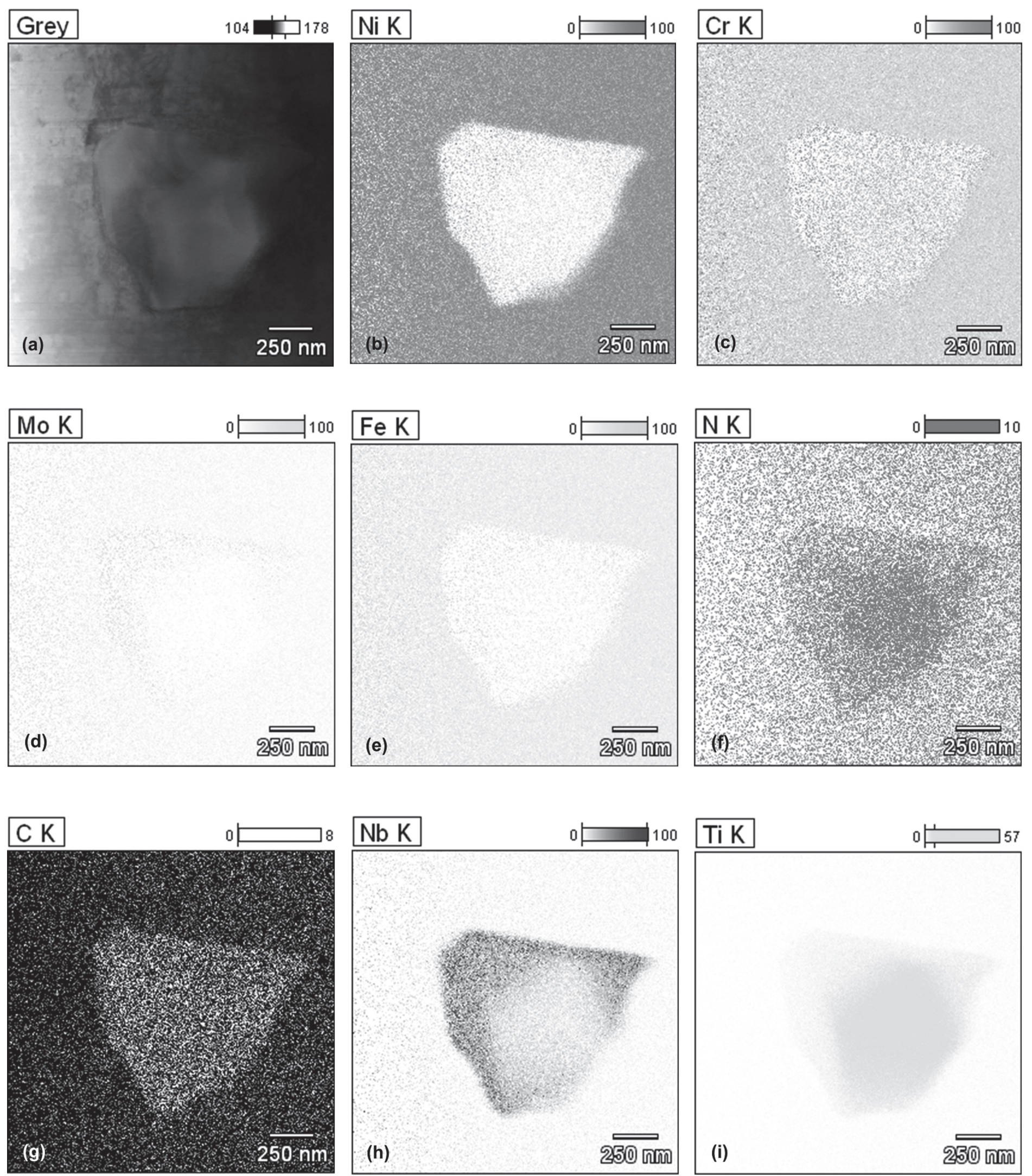

Figure 9. (a) Imagem de campo claro obtida por TEM operando no modo varredura (STEM). Mapeamento químico via EDS mostrando a evolução de TiN para NbC (\% em peso). (b) Níquel; (c) Cromo; (d) Molibdênio; (e) Ferro; (f) Nitrogênio; (g) Carbono; (h) Nióbio; (i) Titânio. 

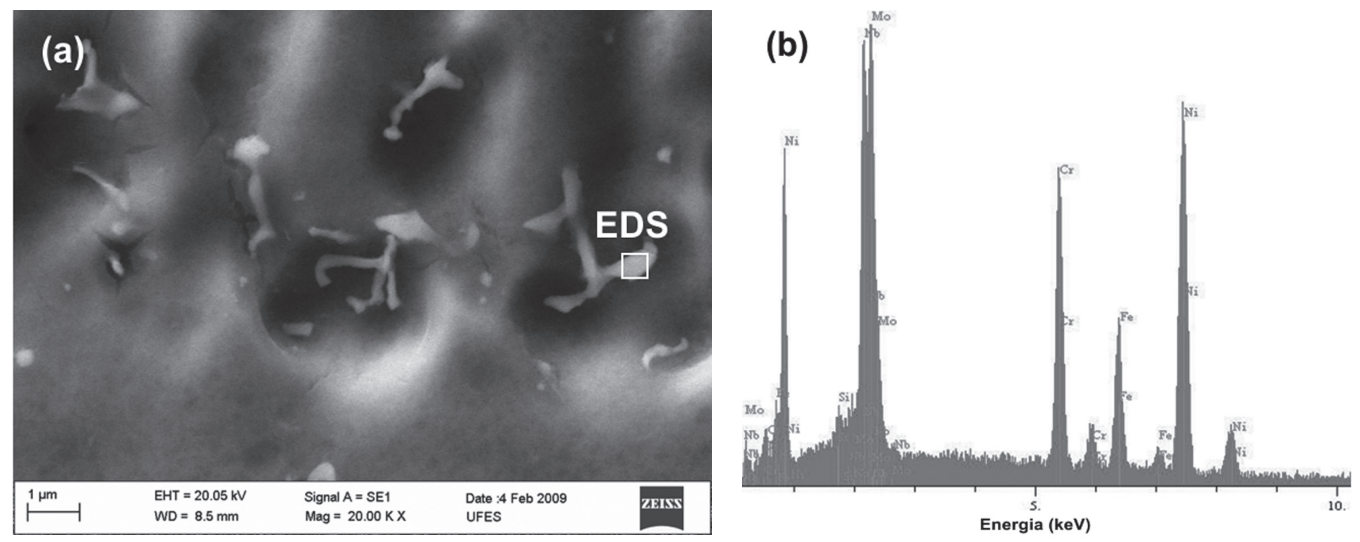

(c)
\begin{tabular}{|l|l|}
\hline Elemento & $\begin{array}{l}\text { Concentração } \\
(\% \text { peso })\end{array}$ \\
\hline $\mathrm{Si}$ & 0,5 \\
\hline $\mathrm{Cr}$ & 13,5 \\
\hline $\mathrm{Fe}$ & 8,3 \\
\hline $\mathrm{Ni}$ & 31,2 \\
\hline $\mathrm{Nb}$ & 27,0 \\
\hline $\mathrm{Mo}$ & 19,5 \\
\hline
\end{tabular}

Figura 10. (a) Micrografia obtida por MEV no modo SE apresentando precipitados alongados presentes na região interdendrítica. (b) Análise química por EDS do precipitado indicado na Figura 10a. (c) Resultado na análise química semi-quantitativa de EDS.
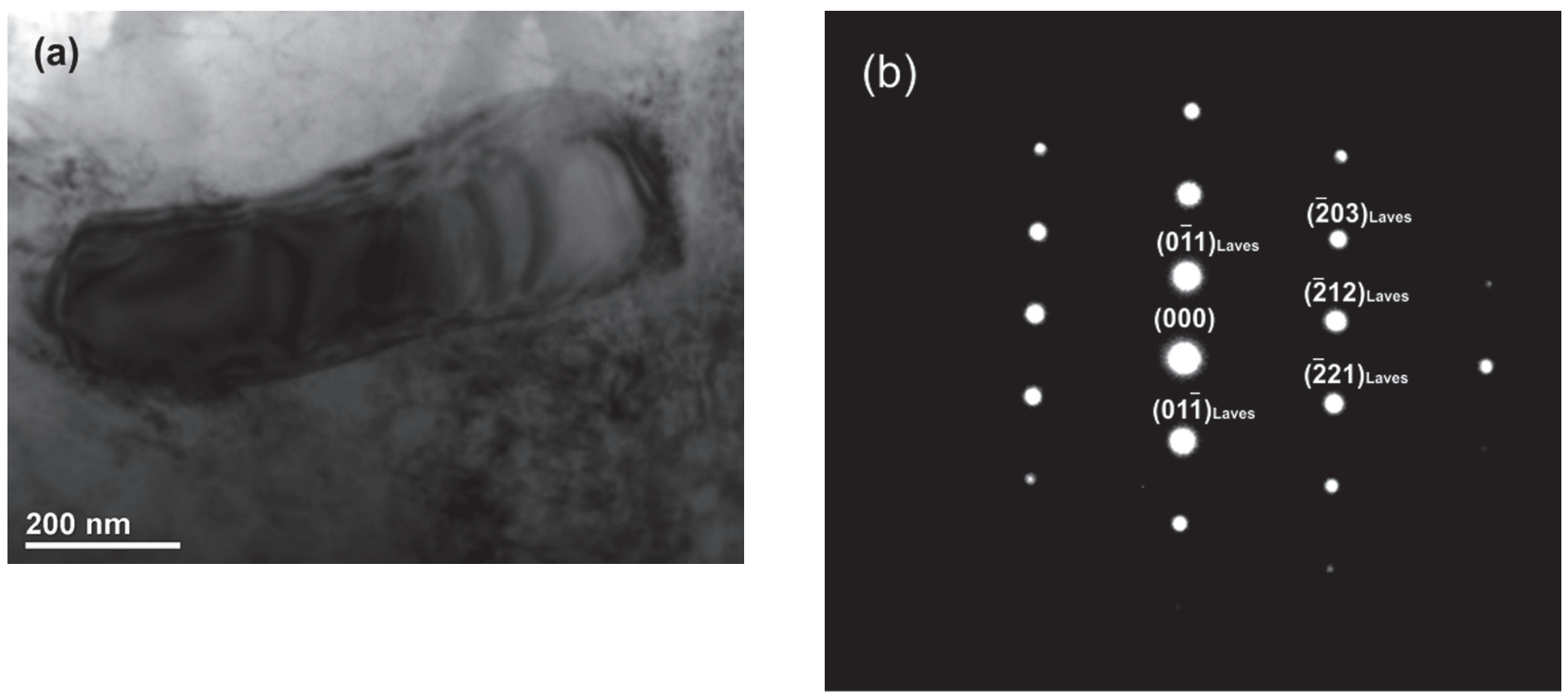

Figure 11. (a) Imagem em campo claro de um precipitado em forma de bastonete obtida por MET. (b) Padrão de difração de elétrons de área selecionada do referido precipitado. Eixo de zona [322] $]=[41-56]$.

Uma segunda morfologia de precipitados bastante observada nas amostras soldadas com a liga 625 foi uma estrutura alongada na forma de bastonetes ou em alguns casos apresentando morfologia eutética. A Figura 10a apresenta alguns destes precipitados na região interdendrítica da matriz g. A análise química de EDS destas partículas revelou um alto teor de $\mathrm{Nb}$, com cerca de $27 \%$ em peso, além de Fe $(8,3 \%), \mathrm{Cr}(13,5 \%)$, Ni $(31,2 \%)$ e Mo (19,5\%) (Figura 10b), a qual é consistente com o reportado para a fase Laves. Considerando que a liga apresenta somente 3,5 a $4,0 \%$ de $\mathrm{Nb}$, tem-se no precipitado um teor de $\mathrm{Nb}$ quase 7 vezes maior do que a matriz. Diferentemente do observado para os precipitados cúbicos nos quais foram detectadas as presenças de $\mathrm{C}, \mathrm{Ne}$ Ti em quantidade significativa. Além disso, no caso dos precipitados alongados houve a presença de um pico de Si.

A análise por microscopia eletrônica de transmissão (MET) indicou que as fases precipitadas com aspecto alongado e morfologia de bastonetes, semelhante às observados nas análises de MEV, correspondem a fases Laves com estrutura hexagonal (a $» 0,476 \mathrm{~nm}, \mathrm{c} » 0,713 \mathrm{~nm}$ ), ricas em $\mathrm{Nb}$, semelhante às observadas por Cieslak [37]. A Figura 11a apresenta uma imagem de MET no modo campo claro de um destes bastonetes. O padrão de difração de área selecionada deste precipitado é apresentado na Figura 11b, o qual foi caracterizado inequivocamente como sendo fase Laves.

Foram observadas ainda grandes colônias de fases secundárias com morfologia eutética lamelar rica em $\mathrm{Nb}$, bem como longas cadeias de estruturas eutéticas ao longo das regiões interdendríticas e intercelulares, como pode ser observado na Figura 12. Estas morfologias são característica das fases Laves em ligas de $\mathrm{Ni}$ contendo $\mathrm{Nb}$. A formação destas colônias de precipitados nas amostras 2 e 3 ocorreu preferencialmente na 


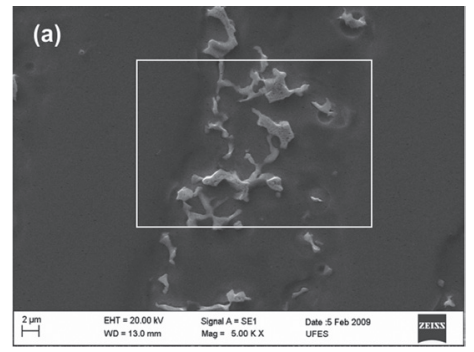

(b)

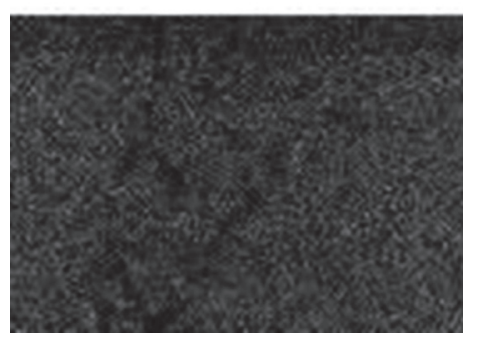

(c)

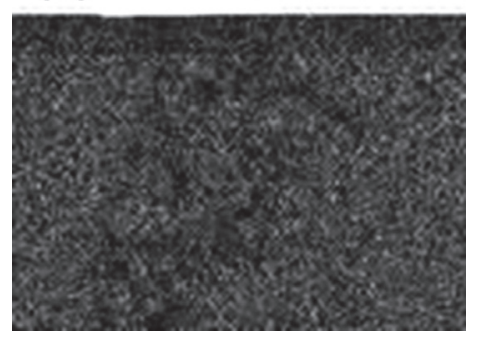

(d) Mo

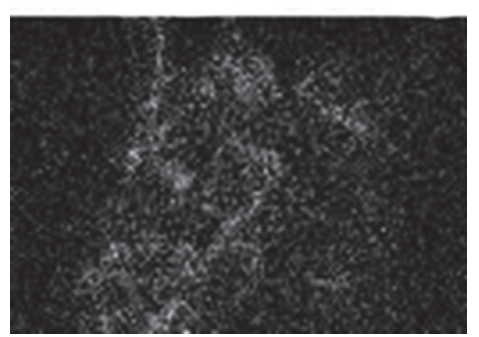

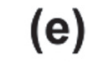

$\mathrm{Nb}$

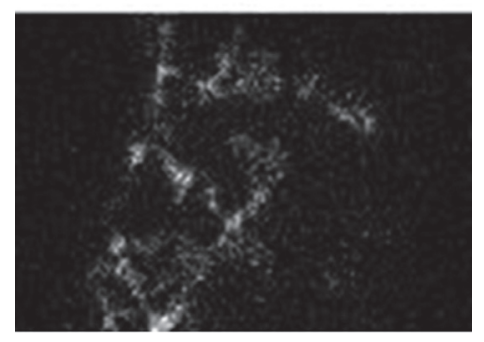

(f)

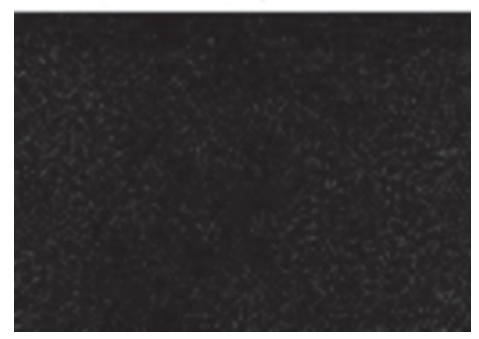

(g)

Si

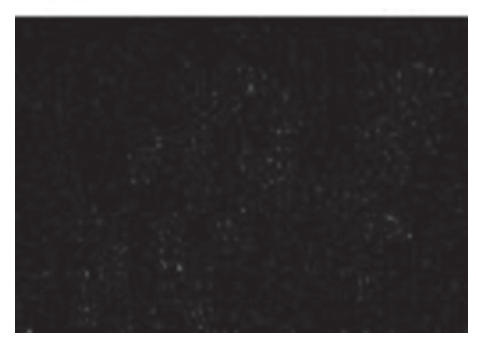

Figura 12. (a) Colonias de fase Laves precipitadas na região interdendrítica. Mapeamento químico obtido por EDS dos elementos (\% em peso): (b) Ni; (c) Cr; (d) Mo; (e) Nb; (f) Fe; (g) Si.

região do metal de solda próximo à superfície do cordão de solda. Tal comportamento é justificado pelo enriquecimento do líquido à frente da interface $\mathrm{S} / \mathrm{L}$, devido o processo de microsegregação de soluto, especialmente Mo e $\mathrm{Nb}$, fazendo com que o líquido remanescente ao final da solidificação torne-se supersaturado nestes elementos, favorecendo a reação eutética L ${ }^{\circledR} \mathrm{g}+$ Laves.

De fato, a morfologia destes eutéticos assemelha-se a algumas formações eutéticas observadas nos trabalhos de Dupont et al. [38,39] e Cieslak et al. [40], a qual foi considerada pelos autores característica de fase Laves rica em $\mathrm{Nb}$. As informações obtidas até então são consistentes com os resultados reportados na literatura. Os teores dos elementos determinados através da análise de EDS são compatíveis com os encontrados por Dupont [10] para a fase Laves rica em $\mathrm{Nb}$, cuja composição química média foi de $18 \%$ de $\mathrm{Fe}, 30,2 \%$ de $\mathrm{Ni}, 11,6 \%$ de $\mathrm{Cr}, 16,7 \%$ de Mo e $22,1 \%$ de $\mathrm{Nb}$, além de $1,1 \%$ de $\mathrm{Si}$, indicando que tanto os precipitados em forma de bastonetes quanto os de morfologia eutética são fases Laves rica em $\mathrm{Nb}$. Cieslak et al. [41] verificaram que durante a solidificação o Si segrega fortemente e participa da formação tanto de fase Laves quanto de carbonetos do tipo $\mathrm{M}_{6} \mathrm{C}$, não sendo observado em carbonetos do tipo $\mathrm{MC}$.

Aformaçãodas fases secundárias nos volumes interdendríticos é atribuída principalmente ao processo de microsegregação de alguns elementos químicos durante a solidificação do metal de solda. Visto que o evento da solidificação ocorre fora do equilíbrio, a segregação de certos elementos pode ocasionar uma supersaturação do líquido ao final da solidificação, fazendo com que este exceda o limite de solubilidade da fase $\gamma$ e sua condição de enriquecimento favoreça a solidificação de outras fases.

A análise da composição química do volume do metal de solda indicou uma forte segregação de elementos como Mo e $\mathrm{Nb}$ para a região interdendrítica, enquanto que elementos como $\mathrm{Ni}$, $\mathrm{Cr}$ e Fe apresentaram um leve empobrecimento nestas regiões (interdendríticas). O perfil de composição química traçado na direção transversal a algumas dendritas denota claramente a variação dos elementos, conforme mostrado na Figura 13. Na região do núcleo da dendrita é observado um significativo aumento no teor de Ni e um leve acréscimo do Fe e do Cr. Para as regiões interdendríticas, indicadas na Figura 13 através de setas, é possível observar um aumento nos teores de Mo e Nb.

Um importante parâmetro que auxilia na investigação do processo de microsegregação durante a solidificação é o coeficiente de distribuição k. Este coeficiente (k) representa a tendência de um dado elemento segregar para o líquido ou compor o sólido durante o processo de solidificação, tendo papel fundamental na compreensão do processo de microsegregação. Elementos com $\mathrm{k}<1$ tendem a segregar para o líquido enquanto elementos com $\mathrm{k}>1$ tendem a segregar para o sólido [37].

A Tabela 4 apresenta as concentrações dos principais elementos (\% em peso) no centro da dendrita $\left(\mathrm{C}_{\mathrm{s}}\right)$ e na região interdendrítica $\left(\mathrm{C}_{\mathrm{i}}\right)$ para a amostra 1 , tendo sido uma soldada com baixo aporte térmico. A análise química foi obtida por EDS. Assumindo condições normais de solidificação, comumente encontradas para processos de soldagem à arco voltaico, tem-se que a região do centro da dendrita, a qual é a primeira região a solidificar, deve apresentar uma concentração $\mathrm{k}_{\mathrm{C} 0}$, na qual $\mathrm{C}_{0}$ é a composição nominal do metal de solda, considerando a diluição com o substrato. Com base na composição do "primeiro" sólido a ser formado $\left(\mathrm{C}_{\mathrm{s}}\right)$, determinada via EDS e apresentado na Tabela 4, e na composição nominal do metal de solda $\left(\mathrm{C}_{0}\right)$ determinada experimentalmente por FRX e apresentada na Tabela 3, foram calculados os valores dos $\mathrm{k}$ através da Equação II, os quais são apresentados também na Tabela 4.

$$
k=\frac{C_{s}}{C_{0}}
$$



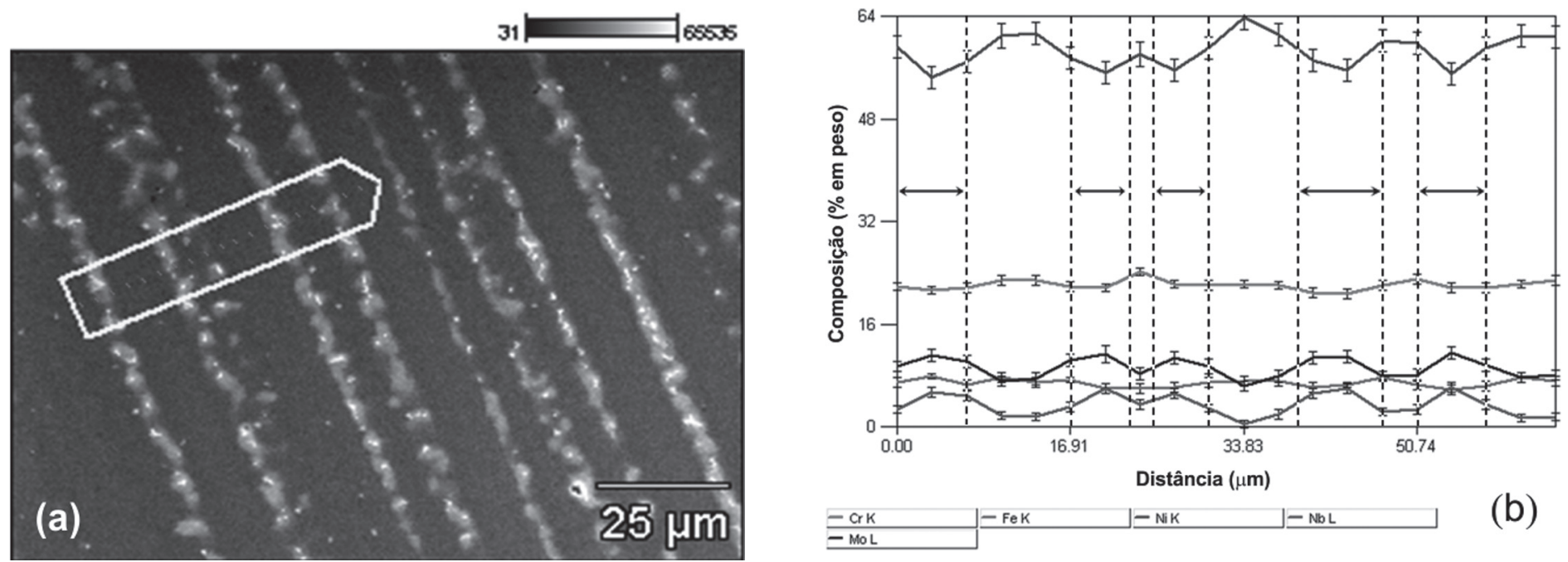

Figura 13. Perfil de composição química evidenciando a segregação de elementos durante a solidificação. As setas indicam a região interdendrítica (\% em peso).

Os coeficientes $\mathrm{k}$ de alguns elementos como o $\mathrm{Ni}$ e o Fe (Tabela 4) apresentaram valores pouco superior a 1, indicando uma leve segregação destes elementos para o sólido. Quanto ao $\mathrm{Cr}$, este apresentou valores também superiores a 1, assim, o seu comportamento segue semelhante aos dos elementos Ni e Fe. Já o Mo apresentou um coeficiente de distribuição inferior a 1, segregando para o líquido e enriquecendo a região interdendrítica ao final da solidificação. Assim como o Mo, o Nb também segregou para o líquido, porém com uma intensidade maior quando comparado ao Mo. É importante destacar que resultados semelhantes foram obtidos para outras condições avaliadas indicando que o comportamento da segregação dos elementos de liga foi praticamente o mesmo, independente do aporte térmico utilizado no presente estudo. Destaca-se ainda que esta forte segregação de $\mathrm{Nb}$ é a principal responsável pela formação das fases secundária observadas na microestrutura dos revestimentos da liga 625 e discutida anteriormente.

De fato, para ligas que contém adição de $\mathrm{Nb}$, como o caso da liga 625 , tem sido apontado na literatura a existência de um perfil característico de segregação, idêntico ao apresentado anteriormente na Figura 13. Cieslak et al. [41] determinaram a distribuição dos elementos químicos ao longo das dendritas através de análise de microsonda. Os autores verificaram que elementos como $\mathrm{Nb}$, Mo, $\mathrm{Ti}$ e $\mathrm{Si}(\mathrm{k}<1)$ segregam fortemente para a região interdendrítica, enriquecendo esta região, enquanto os centros das dendritas tornam-se empobrecidos destes elementos e ricos em $\mathrm{Ni}$ e $\mathrm{Fe}(\mathrm{k}>1)$. Quanto ao $\mathrm{Cr}$, não foram observados indícios de segregação deste elemento para a região interdendrítica. Comportamento semelhante foi observado por Dupont et al. [42]. Isto indica que os resultados do perfil de segregação observado no presente trabalho estão em consonância com o reportado pela literatura.
Tabela 4. Distribuição de elementos químicos (\% em peso) nas regiões dendríticas e interdendríticas e coeficiente de distribuição $\mathrm{k}$.

\begin{tabular}{|c|c|c|c|}
\hline \multirow{2}{*}{ Elemento } & \multicolumn{3}{|c|}{ Amostra 1} \\
\cline { 2 - 4 } & $\mathrm{Cs}$ & $\mathrm{Ci}$ & $\mathrm{K}$ \\
\hline $\mathrm{Ni}$ & $60,1 \pm 2,9$ & $52,6 \pm 1,5$ & 1,03 \\
\hline $\mathrm{Cr}$ & $21,6 \pm 0,7$ & $19,6 \pm 0,8$ & 1,02 \\
\hline $\mathrm{Mo}$ & $7,7 \pm 1,5$ & $12,3 \pm 1,2$ & 0,95 \\
\hline $\mathrm{Nb}$ & $1,6 \pm 0,9$ & $6,5 \pm 2,0$ & 0,50 \\
\hline $\mathrm{Fe}$ & $8,8 \pm 1,0$ & $8,9 \pm 0,8$ & 1,09 \\
\hline
\end{tabular}

Além do $\mathrm{Nb}$, outro importante elemento cujo mecanismo de segregação afeta diretamente o comportamento da liga é o Mo. De acordo com os resultados apresentados no presente estudo, os teores de Mo no centro da dendrita caem para valores próximos de $7 \%$, enquanto a região interdendrítica alcança valores da ordem de $12 \%$, devido a rejeição deste soluto por parte do sólido durante a solidificação. De fato, os resultados da literatura corroboram com os obtidos experimentalmente, mostrando efetivamente que o Mo segrega fortemente para o líquido $(\mathrm{k}<1)$. Este aspecto é importante, pois embora o Mo não seja o principal elemento responsável pela formação das fases secundárias, seus efeitos sobre a resistência à corrosão são notórios, estando diretamente relacionado com a formação da camada passivadora, auxiliando o $\mathrm{Cr}$ na manutenção da camada, especialmente contra o ataque por cloretos, responsáveis pelo processo de corrosão localizada (pites e frestas). Os reflexos de sua segregação sobre a resistência à corrosão da liga foram evidenciados por ensaios eletroquímicos e testes de imersão nos quais o ataque corrosivo foi observado preferencialmente ao longo do centro das dendritas, os quais encontram-se empobrecidos em Mo, conforme apresentado em Silva [24]. 


\section{Conclusões}

Com base nos resultados experimentais apresentados no presente estudo sobre as características microestruturais observadas em revestimentos de soldas dissimilares produzidas com a superliga Inconel 625 e o aço ASTM A516 Gr. 60 foi possível concluir que:

- A zona parcialmente misturada (ZPM) constitui uma zona de transição, variando entre 10 a $100 \mathrm{~mm}$ de espessura, existente entre o revestimento e o substrato e que apresenta uma variação contínua de composição química, desde uma composição muito rica em $\mathrm{Fe}$, próxima à linha de fusão, até a composição do volume do metal de solda correspondendo à composição das ligas à base de níquel.

- A microestrutura dos revestimentos depositados com a liga Inconel 625 foi constituída por uma matriz $\gamma$ com fases secundárias ricas em $\mathrm{Nb}$ tipo Laves e carbonetos/nitretos de $\mathrm{Ti}$ e $\mathrm{Nb}$.

- Precipitados com morfologia cuboidal ricos em Nb e Ti, e com presença de $\mathrm{C}$ e $\mathrm{N}$ observadas no metal de solda não constituem simplesmente carbonetos ou carbonitretos primários do tipo MC, mas sim uma estrutura complexa formada por um núcleo de nitreto de titânio (TiN) e uma casca de carboneto de nióbio $(\mathrm{NbC})$ ou nióbio-titânio (NbTiC).

- A escolha dos parâmetros de soldagem pode influenciar o mecanismo de formação dos eutéticos de fase Laves rica em $\mathrm{Nb}$ responsáveis pela formação das trincas de solidificação.

- O processo de microsegregação do $\mathrm{Nb}$ e do Mo são os principais responsáveis pela formação das fases eutéticas Laves $+\gamma$ associadas diretamente às trincas de solidificação, e pela queda na resistência à corrosão da zona fundida.

\section{Agradecimentos}

Os autores gostariam de agradecer ao Laboratório de Engenharia de Soldagem - ENGESOLDA da UFC. Ao Laboratório de Microscopia Eletrônica - LME do Laboratório Nacional de Luz Síncrotron - LNLS pelo suporte nas análises de MET usando o Microscópio Jeol JEM 2100 HTP e MEV com o Microscópio Jeol JSM 5900 LV. Ao Laboratório de Microscopia Eletrônica da Universidade Federal do Espirito Santo (UFES) pela disponibilização do MEV para a realização de análises. À PETROBRAS pela colaboração no desenvolvimento deste projeto. E aos órgãos de fomento CNPq, FINEP e CAPES pelo suporte financeiro e concessão de bolsa de doutorado.

\section{Referências Bibliográficas}

[1] PEREPEZKO, J.H. The hotter the engine, the better. Science, USA, v. 326, p. 1068-1069, nov. 2009.

[2] ZHANG, Q.; TANG, R.; YIN, K.; LUO, X.; ZHANG, L. Corrosion behavior of Hastelloy C-276 in supercritical water. Corrosion Science, v. 51, p. 2092-2097, 2009.

[3] YIN Z.F.; ZHAO W.Z.; LAI W.Y.; ZHAO X.H. Electrochemical behaviour of Ni-base alloys exposed under oil/ gas field environments. Corrosion Science, v. 51, p. 1702-1706, 2009.

[4] DEACON R.M.; DUPONT J.N.; MARDER A.R. High temperature corrosion resistance of candidate nickel-based weld overlay alloys in a low NOx environment. Materials Science and Engineering A, v. 460-461, p. 392-402, 2007.

[5] LU, K. The future of metals. Science, USA, v.328, p. 319320, 2010.

[6] PIERAGGI B.; MACDOUGALL B.; RAPP R.A. The role of the metal/oxide interface in the growth of passive films in aqueous environments. Corrosion Science, v. 47, p. 247-256, 2005.

[7] YAMAMOTO, Y.; BRADY, M. P.; LU, Z. P.; MAZIASZ, P. J.; LIU, C. T.; PINT, B. A.; MORE, K. L.; MEYER H. M.; PAYZANT, E. A. Creep-resistant, Al2O3-forming austenitic stainless steels. Science, v.316, pp. 433-436, 2007.

[8] COSUlTCHI, A., GARCIAFIGUEROA, E., GARCIABORQUEZ, A., REGUERA, E., YEE-MADEIRA, H., Petroleum Solid Adherence on Tubing Surface. Fuel, v. 80, p. 1963-1968, 2001.

[9] NAFFAKH, H.; SHAMANIAN, M.; ASHRAFIZADEH, F. Influence of Artificial Aging on Microstructure and Mechanical Properties of Dissimilar Welds between 310 Stainless Steel and INCONEL 657. Metallurgical and Materials Transactions A, USA, v. 39A, 2008, pp 2403-2415.

[10] DUPONT, J.N. Solidification of an Alloy 625 Weld Overlay. Metallurgical and Materials Transactions A, USA, v. 27A, 1996, pp 3612-3620.

[11] HODGE, F.G. The History of Solid-Solution-Strengthened Ni Alloys for Aqueous Corrosion Service. JOM Journal of the Minerals, Metals and Materials Society, USA, v. 58, n. 9, p. 2831, sep. 2006.

[12] PATEL, S.J. A Century of Discoveries, Inventors, and New Nickel Alloys. JOM Journal of the Minerals, Metals and Materials Society, USA, v. 58, n. 9, p. 18-20, sep. 2006.

[13] Efeito do teor de carbono Carbonetos sensitização

[14] HAYES, J.R., GRAY, J.J., SZMODIS, A.W., ORME, C.A. Influence of Chromium and Molybdenum on the Corrosion of Nickel-Based Alloys. Corrosion, USA, v. 62, n. 6, p. 491-500, jun. 2006.

[15] DUNN, D.S., PAN, Y.-M., YANG, L., CRAGNOLINO, G.A. Localized Corrosion Susceptibility of Alloy 22 in Chloride Solutions: Part 1 - Mill Annealed Condition. Corrosion, USA, v. 61, n. 11, p. 1078-1085, nov. 2005.

[16] DUNN, D.S., PAN, Y.-M., YANG, L., CRAGNOLINO, G.A. Localized Corrosion Susceptibility of Alloy 22 in Chloride Solutions: Part 2 - Effect of Fabrication Process. Corrosion, USA, v. 62, n. 1, p. 3-12, jan. 2006.

[17] DUPONT, J. N. Microstructural development and solidification cracking susceptibility in the fusion zone of a stabilized stainless steel. Welding Journal, USA, v. 78, n. 7, p. 253-263, jul. 1999.

[18] BANOVIC, S. W., DUPONT, J. N., MARDER, A. R. Dilution and microsegregation in dissimilar metal welds between super austenitic stainless steel and nickel base alloys. Science and Technology of Welding and Joining, v. 7, n. 6, p. 374-383, 2002. 
[19] GITTOS M. F., GOOCH T. G. Effect of iron dilution on corrosion resistance of Ni-Cr-Mo alloy cladding. British Corrosion Journal, UK, v. 31, n. 4, p. 309-314, apr. 1996.

[20] SAVAGE, W. F., NIPPES, E. F., SZEKERES, E. S. A study of fusion boundary phenomena in a low alloy steel. Welding Journal, USA, v. 55, p. 260-268, 1976.

[21] BAESLACK III, W. A., LIPPOLD, J. C., SAVAGE, W. F. Unmixed zones formation in austenitic stainless steel. Welding Journal, USA, v. 58, n. 6, p. 169-176, jun. 1979.

[22] WANG, Z., XU, B., YE, C. Study of martensite structures at the weld interface and fracture toughness of dissimilar metal joints. Welding Journal, USA, v. 72, n. 8, p. 397-402, aug. 1993. [23] ROWE, M. D., NELSON, T. W., LIPPOLD, J. C. Hydrogeninduced cracking along the fusion boundary of dissimilar metal welds. Welding Journal, USA, v. 78, n. X, pp. 31-37, 1999.

[24] SILVA, C. C. Revestimentos de ligas de níquel depositadas pelo processo TIG com alimentação de arame frio - Aspectos operacionais e metalúrgicos: 2010. 319p. Tese (Doutorado) - Departamento de Engenharia Metalúrgica e de Materiais, Universidade Federal do Ceará, Fortaleza-CE.

[25] SILVA, C.C., MIRANDA, H.C., FARIAS, J.P., ABREU, H.F.G. Chemistry and Crystallographic Evaluation of Ni-based Alloy and Steel Dissimilar Interface. In: International Trends of Welding Research, $9^{\text {th }}$, Chicago. Proceedings... Materials Park, OH: ASM international, 2012.

[26] FOX, R. W., MCDONALD, A. T., PRITCHARD, P. J. Introduction to fluid mechanics. 6 ed. John Wiley \& Sons Inc. 2004.

[27] SAVAGE, W.F., NIPPES, E.F., SZEKERES, E.S. A study of fusion boundary phenomena in a low alloy steel. Welding Journal, USA, v. 55, pp. 260-68, 1976.

[28] YANG, Y.K., KOU, S. Macrosegregation mechanisms in arc welds made with dissimilar filler metals. Science and Technology of Welding and Joining. v. 15, p. 15-30, 2010.

[29] YANG Y. K., KOU, S. Analysis of macrosegregation near fusion boundary in fusion welding, Science and Technology of Welding and Joining. 13, 318-26 (2008).

[30] V.C.M. BEAUGRAND, L.S. SMITH, M.F. GITTOS, Subsea Dissimilar Joints: Failure Mechanisms and Opportunities for Mitigation. In: CORROSION 2009. Atlanta, 2009. Proceedings... Houston, TX: NACE International, 2009.

[31] KEJELIN, N. Z., BUSCHINELli , J. A., POPE, A. M. Influence of Welding Parameters on the Formation of Partially Diluted Zones of Dissimilar Metal Welds. Soldagem \& Inspeção, Brasil, v. 12, p. 195-203, 2007.

[32] SILVA, C.C., MIRANDA, H.C., MOTTA, M.F., FARIAS, J.P., AGUIAR, W.M. Influence of Welding Operational Conditions on Partial Mixed Zone Formation in Ni-Based Dissimilar Weld Overlay. In: International Trends of Welding Research, 9th, Chicago. Proceedings... Materials Park, OH: ASM international, 2012.

[33] ISO 10423. Petroleum and natural gas industries -- Drilling and production equipment -- Wellhead and christmas tree equipment. ISO Standard, Geneva, Switzerland, 2009.

[34] SILVA, C.C. MIRANDA, E.C., MOTTA, M.F., MIRANDA, H.C., FARIAS, J.P. Dilution control of weld overlay superal overlay superal superalloys using taguchi method. In: International Conference on Ocean, Offshore and Artic Engineering OMAE2012, 31st, 2012, Rio de Janeiro. Proceedings... Houston, TX: American Society of Mechanical Engineering ASME, 2012.

[35] W. LENGAUER, in: R. RIEDEL (Ed.), Transition Metal Carbides, Nitrides and Carbonitrides, Handbook of Ceramic Hard Materials, vol. 1, Wiley-VCH, Weinheim, 2000, pp. 202252.

[36] SILVA, C.C., AFONSO, C.R.M., MIRANDA, H.C., RAMIREZ, A.J., FARIAS, J.P. Microstructure of alloy 625 weld overlay. In: AWS Fabtech Conference, 2011, Chicago, IL, USA, Proceedings... Miami, FL: American Welding Society AWS, 2011.

[37] CIESLAK, M.J. The welding and solidification metallurgy of alloy 625. Welding Journal, USA, v. 70, n.2, p.49-56, feb. 1991.

[38] DUPONT, J.N., ROBINO, C.V., MICHAEL, J.R., NOTIS, M.R., MARDER, A.R. Solidification of Nb-Bearing Superalloys: Part I. Reaction Sequences. Metallurgical and Materials Transactions A, USA, v.29A, p.2785-2796, nov. 1998. [39] DUPONT, J.N., ROBINO, C.V., MARDER, A.R., NOTIS, M.R. Solidification of Nb-Bearing Superalloys: Part II. Pseudoternary Solidification Surfaces. Metallurgical and Materials Transactions A, USA, v.29A, p.2797-2806, nov. 1998. [40] CIESLAK, M. J., KNOROVSKY, G. A., HEADLEY, T. J., ROMIG Jr., A. D. The Solidification Metallurgy of Alloy 718 and Other Nb-Containing Superalloys, In: Superalloys 718 Metallurgy and Applications, 1989. Proceedings... Warrendale, PA: The Minerals, Metals and Minerals Society, p. 59-67, 1989. [41] CIESLAK, M.J., HEADLEY, T.J., KOLLIE, T., ROMIG, A.D. A melting and solidification study of alloy 625 . Metallurgical Transactions A, USA, v. 19A, p.2319-2331, set. 1988.

[42] DUPONT, J. N., BANOVIC, S. W., MARDER, A. R. Microstructural Evolution and Weldability of Dissimilar Welds between a Super Austenitic Stainless Steel and Nickel-Based Alloys. Welding Journal, USA, v. 82, n. 6, pp. 125-56, jun. 2003. 